\title{
Arbor
}

\section{Tipología y socialización de las familias españolas}

\author{
Javier Elzo
}

Arbor CLXXVIII, 702 (Junio 2004), 205-229 pp.

En esta conferencia vamos a presentar una Tipología de familias españolas fruto de un trabajo colectivo dirigido por Eusebio Megías, elaborado en la FAD así como su capacidad socializadora. Procederemos en dos tiempos. En un primer momento presentaremos cuales son, a tenor de diferentes trabajos en los que hemos participado recientemente, tanto en el marco de las investigaciones de la Fundación Santa María como en las que hemos llevado a cabo en la Universidad de Deusto, los principales de agentes de socialización de la juventud actual y, de modo particular, el papel de la familia entre ellos. En un segundo momento presentaremos la tipología propiamente dicha en base al estudio arriba mencionado al que hemos añadido algunas consideraciones posteriores ${ }^{1}$.

\section{La familia como agente de socialización}

Como acabamos de señalar en este primer punto nos detendremos en los resultados de los estudios que la Fundación Santa María ha realizado sobre la juventud, cuando se detiene en la familia como agente de socialización. En un primer momento haremos un sucinto repaso a los datos ya existentes, completados con los de otros estudios, particularmente de INJUVE y en un segundo apartado avanzaremos, en base a un estudio inédito, el papel de la familia cuando de una dimensión de socialización fuerte se trata, la socialización en vistas a una posible vocación religiosa. 


\subsection{La familia como agente genérico de socialización en la juventud española}

En los estudios sobre la juventud de la Fundación Santa María se analiza en diferentes capítulos esta cuestión central (uno de los ejes transversales de todas las investigaciones de la Fundación), abordada bajo la fórmula de preguntarles, muy al inicio del cuestionario: «Dónde piensas tu que se dicen las cosas más importantes en cuanto a ideas e interpretaciones del mundo». Es una cuestión ya clásica de los estudios de juventud donde se incide en la importancia de los valores (y sus agentes de transmisión) para comprender los comportamientos de las personas. En la tabla 1 presentamos la evolución en los últimos años (desde que tenemos la cuestión así formulada) del «locus» donde según los jóvenes españoles se dicen las cosas más importantes para orientarse en la vida.

TABLA 1. Dónde se dicen las cosas más importantes en cuanto a ideas e interpretaciones del mundo

(Evolución en los últimos años. Respuestas, en porcentajes)*

\begin{tabular}{l|rrrr}
\hline & $\mathbf{1 9 8 9}$ & $\mathbf{1 9 9 4}$ & $\mathbf{1 9 9 9}$ & $\mathbf{1 9 9 9 - 1 9 8 9}$ \\
\hline En casa, con la familia & 23 & 50 & 53 & $+30 \%$ \\
Entre los amigos & 31 & 35 & 47 & $+16 \%$ \\
En los medios de comunicación & 34 & 30 & 34 & $=$ \\
En los libros & 28 & 20 & 22 & $-6 \%$ \\
En los centros de enseñanza (profesores) & 14 & 21 & 19 & $+5 \%$ \\
En la Iglesia (sacerdotes, parroquias, & 16 & 4 & 3 & $-13 \%$ \\
obispos) & 16 & 4 & - & $-14 \%$ \\
En los partidos políticos** & & & 1 & $-3 \%$ \\
En otros & 4 & 1 & 3 & $-5 \%$ \\
En ningún sitio & 8 & 2 & - & $-4 \%$ \\
Ns/Nc & 4 & 0,4 & 3.853 & \\
$N=$ & 4.548 & 2.028 & &
\end{tabular}

* La suma de respuestas es superior a $100 \%$ en cada columna porque los jóvenes podían dar tantas respuestas, indicar tantos espacios de socialización como quisieran.

** No se preguntó por los partidos políticos el año 1999. Nadie los mencionó en el test piloto.

Fuente: J. Elzo (dir).Jóvenes españoles 99. Fundación Santa María, Ediciones SM.

El medio más influyente, por tanto, es el de los grupos primarios: familia y amigos. Que, además, ha ido ganando terreno a través de los años, en detrimento de los libros y con fluctuaciones la escuela. Los medios de comunicación convencionales (prensa, radio y TV) vienen luego, mante- 


\section{Tipología y socialización de las familias españolas}

niéndose en esta posición a lo largo de los años. Y los que siguen perdiendo fuerza son los medios institucionales: Iglesia y partidos. La Iglesia y los partidos políticos, asociaciones de carácter ideológico en sentido amplio, han dejado prácticamente de contar como agencias de socialización. En 1989 eran citadas cada una por el 16\% de jóvenes; en 1994 por un $4 \%$. En 1999 se omitió por irrelevante la cuestión sobre la influencia socializadora de los partidos políticos (nadie los señaló en el test piloto) y se mantuvo la de la Iglesia que solamente la citaron el 2,7\% de los jóvenes españoles.

La red social de los amigos ha registrado un fuerte ascenso en los jóvenes como agente de socialización. Con ello se le da todavía más peso a los grupos primarios frente a los institucionales, lo que es una tendencia que ya se venía produciendo años atrás. Esto es indicador evidente del espacio privilegiado que ocupan en la socialización juvenil. En efecto, los amigos conforman el espacio en el que las relaciones están menos formalizadas, son más horizontales (junto a los medios de comunicación; pero frente a estos, los adolescentes son más pasivos y con menor o nula interacción), son más próximas, con todo lo que ello conlleva de participación en experiencias comunes, muchas veces en un marco no normativizado (o no formal y visiblemente normativizado), con la percepción de vivir en libertad, de estar con los suyos, sin tutelas, aspectos estos que, en plena edad de experimentación y descubrimiento, tienen una capacidad de penetración, quizá epidérmica o puntual, pero no por ello menos trascendente en un período de su vida, en el período que ahora están viviendo. Añadamos que en este ámbito la noche, la dimensión de la noche, es central en la socialización de los adolescentes españoles.

Volviendo al tema de la familia, González Anleo, comentando la tabla anterior (Jóvenes españoles 99, pág. 125) y la evolución de los agentes de socialización, indica acertadamente que «aunque en la tabla anterior se ha manejado un solo indicador, los datos apuntan inequívocamente el papel central de la familia en la socialización, seguida ahora muy de cerca por el grupo de amigos, que hace diez años la superaba en influencia socializadora. El papel y poder socializador de los padres ha sido recientemente puesto en duda por Fernando Savater, que ha hablado del eclipse de la familia (1997: 55-89), atribuyéndolo a la crisis de autoridad de la familia y a la influencia de la TV que desvela a los niños los misterios de la vida, les disipa las nieblas cautelares de la ignorancia, lo cuenta todo..., actuando así de catalizador y acelerador de los ingredientes de la educación infantil. Pero la tabla no deja lugar a dudas: la familia sigue ocupando un puesto privilegiado en la transmisión de saberes fundamentales, no solo de hábitos, habilidades y pautas de convivencia». 
Detengámonos, brevemente, en la distribución por género y edad de los resultados de la tabla anterior pero limitados al año 1999. Es lo que puede consultarse en la tabla 2.

TABLA 2. ¿Dónde se dicen, para ti, las cosas más importantes en cuanto a ideas e interpretaciones del mundo?

(Respuestas en porcentajes*, según género y edad)

\begin{tabular}{l|rrr|rrr}
\hline & \multicolumn{3}{|c|}{ Género } & \multicolumn{3}{c}{ Edad } \\
\hline & $\mathbf{9 9}$ & $\boldsymbol{H}$ & $\mathbf{M}$ & $\mathbf{1 5 - 1 7}$ & $\mathbf{1 8 - 2 0}$ & $\mathbf{2 1 - 2 4}$ \\
\hline En casa, con la familia & 53 & 50 & 56 & 53 & 51 & 55 \\
Entre los amigos & 47 & 48 & 46 & 44 & 48 & 49 \\
En los medios de comunicación & 34 & 33 & 34 & 31 & 35 & 34 \\
En los libros & 22 & 21 & 23 & 18 & 22 & 25 \\
En los centros de enseñanza & 19 & 17 & 20 & 23 & 17 & 16 \\
(profesores) & & & & & & \\
En la Iglesia (sacerdotes, parroquias, & 2,7 & 2.6 & 2,8 & 3,9 & 2,0 & 2,3 \\
obispos) & & & & & & \\
En otros & 0,6 & 0,6 & 0,7 & 0,1 & 0,6 & 1,1 \\
En ningún sitio & 2,6 & 3,0 & 2,2 & 1,9 & 2,7 & 3,1 \\
Ns/Nc & 1,1 & 1,4 & 0,7 & 1,6 & 0,6 & 1,0 \\
N & 3.853 & 1.966 & 1.887 & 1.188 & 1.162 & 1.503 \\
\hline
\end{tabular}

* La suma de respuestas es superior al 100\% en cada columna porque los jóvenes podían dar tantas respuestas, indicar tantos espacios de socialización como quisieran.

Fuente: Jóvenes españoles 99. Fundación Santa María, Ediciones SM.

Si analizamos los datos atendiendo al género y edad de los adolescentes y jóvenes constatamos lo siguiente. En lo que al género se refiere hay que decir que apenas hay diferencias en las estimaciones de los chicos y de las chicas. Para ellos y para ellas el ranking es el mismo. Las chicas se decantan ligeramente al alza, por conceder más importancia que los chicos a la familia, a la escuela y a los libros. Los chicos, por su parte, también muy ligeramente por encima de las chicas, se decantan por dar más importancia a los amigos.

Respecto de la edad, hay que resaltar que la importancia de la familia, como espacio de socialización, es prácticamente idéntica en cualquier franja de edad considerada. Si me apuran señalaría que es entre los 18 y 20 años cuando desciende un tanto el papel de la familia, en la primera juventud, para remontar, perceptiblemente, en la segunda, entre los 21 y los 24 años. Pero todo dentro de unos valores similares. Esto nos hace 


\section{Tipología y socialización de las familias españolas}

decir que estamos ante un fenómeno de generación y no ante un fenómeno de edad. Estamos ante una nueva generación, una generación diferente de otras generaciones, incluso próximas en el tiempo. Sin ir más lejos, los jóvenes españoles de los ochenta (y en gran medida también los europeos) son diferentes de estos de final de siglo.

Por lo demás, los amigos adquieren una mayor relevancia a medida que avanzan en edad, así como los libros, descendiendo por el contrario, al ir haciéndose mayores, la importancia que conceden a la escuela. En fin, los medios de comunicación social aparecen como factores de socialización con el mismo peso, independientemente de la edad. Pero lo esencial, de ahí el subrayado, es que estamos ante un fenómeno de generación que va más allá de la edad y del género.

Sí, la familia ocupa un espacio central en la vida de los jóvenes. De esto no hay duda Los jóvenes españoles de 15 a 24 años viven con sus padres en su gran mayoría: el $92,5 \%$. El resto lo hacen con su mujer, con su pareja el $4 \%$, solos el $1,4 \%$, con un amigo el $1,2 \%$, y el $0,9 \%$ en otras situaciones. Pero entre los adolescentes en edades comprendidas entre los 15 y los 17 años el 98,6\% viven con sus padres. Anotemos también que los jóvenes españoles, después de los italianos, son los jóvenes europeos que más tarde abandonan el hogar familiar. Aunque no fuera más que por estos elementales datos estadísticos, podemos pensar que hay una realidad sociológica específica a la familia española en el universo simbólico de la sociedad española. Además, las Encuestas de la juventud, desde 1960 hasta 1999, nos señalan que el anclaje de los jóvenes españoles en su familia viene de hace más de cuarenta años. Es lo que nos indica la tabla 3.

La tabla muestra una más que llamativa persistencia del nicho familiar como lugar donde habitan nuestros adolescentes. Nueve de cada diez adolescentes españoles entre los 15 y los 24 años siguen viviendo con sus padres. Las diferencias son escasas a lo largo de cuatro décadas, luego más de dos generaciones. Será difícil encontrar en la sociología española de los últimos cuarenta años una tabla similar a la presente. La sociedad española, en la que se han producido cambios profundos, mantiene por el contrario una continuidad en la «fidelidad» de los adolescentes españoles al hábitat familiar. Tanto cuando la evolución demográfica señalaba un número grande de hijos por familia (hasta el año 1990, más o menos) como cuando la media de un hijo por familia es la norma. La evolución de valores (liberalidad en las relaciones sexuales, aumento de las parejas de hecho, descenso de los matrimonios canónicos), así como el aumento de las parejas separadas o divorciadas, no tienen correlato con la salida de los hijos del hogar familiar. La explicación del paro juvenil es absoluta- 
mente insuficiente para explicar este estado de cosas, pues hemos pasado de períodos de casi pleno empleo a dar las mayores tasas de paro juvenil en Europa, triplicando incluso las cifras de la media europea, para abocar a trasladar el tema del empleo de su mayor o menor frecuencia a la cuestión de calidad del empleo exigible, situación en la que nos encontramos actualmente en la gran mayoría de la geografía española. Algo similar cabe decir del tema de la vivienda, por señalar los dos órdenes de factores que se esgrimen habitualmente para explicar la persistencia de los jóvenes españoles en su hogar, que solo encuentra parangón en Europa, en la sociedad italiana (ver Elzo 98).

TABLA 3. Evolución del tipo de convivencia de los jóvenes desde 1960 hasta el año 2002 (En porcentajes)

\begin{tabular}{|c|c|c|c|c|c|c|}
\hline & 1960 & 1975 & 1989 & 1994 & 1998 & 2002 \\
\hline 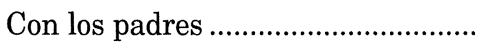 & 90,5 & 80,7 & 89 & 90 & 93 & 87 \\
\hline Con alguien de la familia .................. & 3,6 & 3,1 & $*$ & $*$ & $*$ & $*$ \\
\hline 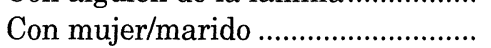 & $*$ & $*$ & 6 & 6 & 2 & 4 \\
\hline Con compañera/compañero.............. & $*$ & * & 1 & 1 & 2 & $*$ \\
\hline Con amigo/a o grupo de amigos ....... & * & $*$ & 1 & 1 & 1 & 6 \\
\hline 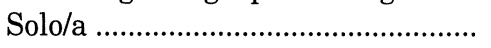 & $*$ & $*$ & 1 & 1 & 1 & $*$ \\
\hline Otros & $*$ & $*$ & 3 & 1 & 1 & 3 \\
\hline En residencia o pensión ..................... & 2,4 & 6,8 & $*$ & * & $*$ & $*$ \\
\hline En piso de alquiler o propio .............. & 1,2 & 7,3 & * & $*$ & $*$ & * \\
\hline 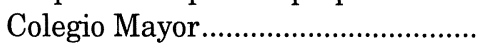 & 0,5 & 2,1 & $*$ & $*$ & $*$ & $*$ \\
\hline 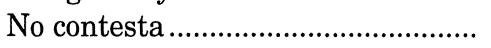 & $\cdot 1,8$ & - & $*$ & $*$ & $*$ & $*$ \\
\hline$N=$ & 1.316 & 3.347 & 4.548 & 2.208 & 3.853 & 1.075 \\
\hline
\end{tabular}

* No se preguntó.

Fuente: Estudios de la Fundación Santa María. Elaboración hasta 1999, Pedro González Blasco en Jóvenes españoles 99, página, 197. Los datos de 2002 son inéditos y provienen de una investigación en fase de estudio de la Fundación Santa María.

De todas las maneras tamaña cuestión no cabe zanjarla con unas pocas tablas, aún en su evolución en el tiempo. Es significativo, en todo caso, que en otras investigaciones se llega a las mismas consideraciones. Así en nuestra serie Drogas y Escuela de la que presentamos la sexta investigación en febrero de 2003, así como en los estudios de INJUVE, de los del Grupo Europeo de Estudio de los valores en sus aplicaciones a España etc., etc. Nos limitamos a presentar aquí la última investigación en la que hemos participado con esta cuestión específica, en el marco de los trabajos que llevamos a cabo en el Instituto de Drogodependencias de la Universidad de Deusto, y que aún no sido publicado ${ }^{2}$. 
Tipología y socialización de las familias españolas

\subsection{La familia como agente de socialización entre los escolares vitorianos}

En Noviembre de 2002 se procedió a administrar un cuestionario, ya validado en estudios anteriores entre escolares de San Sebastián en los homónimos de la ciudad de Vitoria. El estudio fue encargado por el Ayuntamiento de Vitoria al Instituto de Drogodependencias de la Universidad de Deusto. El universo correspondiente a la investigación es el alumnado de la Enseñanza Secundaria Obligatoria (ESO), del Bachillerato LOGSE y del grado medio de Formación Profesional (FP), de las redes educativas pública y privada. El ámbito del estudio es el término municipal de Vitoria/Gasteiz. El número total de componentes de este universo, para el curso escolar 2001-2002, fue de 14.951 alumnos y alumnas, del que se seleccionaron 1891 escolares mediante selección primaria de aulas escolares en diferentes centros. La designación de centros educativos fue establecida con probabilidad proporcional, según su tamaño medido en número de alumnos y de acuerdo a su representación en las redes de enseñanza, centros públicos y privados, diferenciando -en estos últimoslos colegios religiosos, los laicos y las ikastolas. De los 34 centros existentes se encuestó en 18 de ellos, en 97 aulas Fueron encuestados/as 978 chicos y 913 chicas en 97 aulas de 18 centros educativos en las Redes Pública y Privada (religiosa, ikastolas y laica).

Se les formuló idéntica cuestión a la de la investigación de la Fundación Santa María, aunque se les propusieron algunos ítems más de respuesta y no se estableció número máximo de respuestas posibles. Esto y la diferencia de edades en el universo de ambos estudios explican los resultados numéricamente divergentes aunque convergentes en el ranking de espacios citados, como aquellos en los que se dicen las cosas más importantes para orientarse en la vida. Reproducimos los resultados de la encuesta de Vitoria en la tabla $n^{\circ} 4$

El auge en la elección de la familia como marco prioritario de orientación para los jóvenes es un hecho que viene produciéndose de forma imparable desde hace años. También es habitual que para las chicas sea ligeramente más decisiva y que esa trascendencia que le conceden desde niños supere incluso los inevitables choques de la preadolescencia y se mantenga hasta la juventud, incrementándose en esta investigación entre los mayores, lo que no deja ser significativo.

Es un hecho constatado que los jóvenes se influyen en gran medida entre amigos. Sin embargo en sus respuestas posicionan a sus amistades en segundo lugar y lo hacen a considerable distancia de la familia (30 
puntos por debajo). Ésta es una constante que no deja de sorprender a los padres, que tienen una percepción de su influencia en los hijos bastante menos rotunda. Suele ocurrir también, tal como en esta ocasión se confirma, que las chicas, en estas edades concretas, se apoyen más en sus amistades que los chicos. Por otra parte la evolución en función de la edad refleja un incremento paralelo al aumento de los años hasta cumplir los 18, para acercarse al valor medio a los 19 años.

TABLA 4. Dónde se dicen las cosas más importantes para orientarse en la vida (Escolares de Vitoria) (En \%)*

\begin{tabular}{lccccccc}
\hline & Todos & Chicos & Chicas & $\begin{array}{c}\mathbf{1 2 - 1 3} \\
\text { años }\end{array}$ & $\begin{array}{c}\mathbf{1 4 - 1 5} \\
\text { años }\end{array}$ & $\begin{array}{c}\mathbf{1 6 - 1 8} \\
\text { años }\end{array}$ & $\begin{array}{c}\mathbf{1 9} \mathbf{y} \\
\text { más }\end{array}$ \\
\hline Familia & 92 & 91 & 93 & 91 & 91 & 92 & 96 \\
Amigos & 62 & 57 & 68 & 47 & 60 & 73 & 65 \\
Colegio & 55 & 54 & 57 & 50 & 57 & 58 & 52 \\
Libros & 23 & 23 & 23 & 24 & 21 & 22 & 37 \\
M.C.S & 21 & 22 & 20 & 20 & 25 & 18 & 12 \\
Iglesia & 10 & 12 & 8 & 12 & 11 & 9 & 9 \\
Internet & 8 & 9 & 6 & 9 & 10 & 5 & 3 \\
Partidos Políticos & 3 & 4 & 2 & 3 & 3 & 3 & 3 \\
Pareja & 3 & 3 & 3 & 1 & 3 & 3 & 11 \\
Ningún sitio & 2 & 3 & 1 & 2 & 2 & 2 & 1 \\
Total & 1.891 & 978 & 913 & 462 & 560 & 802 & 67 \\
\hline
\end{tabular}

* No suman $100 \%$ por ser respuestas múltiples

Fuente: Elzo, Laespada «El consumo de drogas en escolares vitorianos. Vitoria.2003». Inédito. No publicado.

Los centros educativos son considerados referentes de interés para más de la mitad de los encuestados y levemente más para las encuestadas. Esta postura es coherente con el hecho de que las chicas estén más integradas en el marco escolar y obtengan mejores resultados académicos, como sabemos bien los docentes. $\mathrm{Al}$ ir creciendo se van desenvolviendo más cómodamente en el colegio, pero el aumento de satisfacción se detiene y desciende al llegar a los mayores (19 años), lo que ya nos muestran con más claridad aún en los estudios con universitarios. Además en ese grupo de los mayores de 18 años se sitúan los repetidores de curso.

La lectura y los medios de comunicación social no llegan a influir en la cuarta parte de los y las escolares. Las chicas priman un poco más los 


\section{Tipología y socialización de las familias españolas}

libros -ellas tienen un mayor hábito de lectura- y los chicos los medios de comunicación social. Al controlar la edad vemos que los mayores tienden a apreciar la lectura mientras los más jóvenes priorizan a los M.C.S.

La Iglesia merece la consideración del $10 \%$ de los jóvenes y, tal y como viene ocurriendo últimamente, es más valorada por los chicos que por las chicas, a la vez que su trascendencia es inversa a la edad cumplida, si bien sin grandes cambios entre estos escolares de Vitoria.

En cuanto a la utilización de Internet, goza de mayor predicamento entre los chicos y entre los de 12 a 15 años. En este punto no cabe señalar la evolución, porque es la primera vez que lo incluimos en este listado pero hay algo que es ya muy significativo: los escolares ven en Internet básicamente un instrumento de diversión y juego, más que de socialización.

Los partidos políticos continúan con una presencia casi testimonial, bastante más considerados por los chicos y sin que la edad influya prácticamente en su escasa valoración.

La posibilidad abierta en la que los encuestados apuntaron a sus parejas como agente de referencia aparece en penúltimo lugar, con importancia similar para chicos y chicas pero significativamente incrementada entre los mayores, más en edad de tener pareja. Respecto a la valoración de esta respuesta espontánea hay que considerar que su peso real es superior al porcentaje alcanzado, comparativamente a los otros, por el valor que le da el haber surgido de los propios encuestados sin que hubiera estado propuesta en el Cuestionario.

\section{Una tipología de familias españolas}

El año 2002 publicó la Fundación de Ayuda a la Drogadicción (FAD) un largo y laborioso trabajo en el que más allá del tema específico de la drogadicción queríamos analizar las «relaciones internas» en las familias españolas. Para ello se llevó a cabo un trabajo de campo que, salvo ignorancia por nuestra parte, es absolutamente inédito en el conjunto de la sociedad española, pues se administró un mismo cuestionario, idéntico en su practica totalidad, a una muestra representativa de hijos e hijos entre los 14 y 20 años y sus padres (sea el padre, sea la madre, aleatoriamente) de toda la población española. El trabajo de campo con un análisis cualitativo con cuatro grupos de discusión de ocho personas cada grupo $^{3}$. Un capítulo de esta investigación comprendía una tipología de familias españolas, capitulo en el que trabajé particularmente. Las pági- 
nas que siguen están parcialmente extraídas de ese capítulo al par que completadas con otras consideraciones y análisis posteriores.

Una tipología, toda tipología, es un intento de distinguir en un universo concreto una serie de grupos lo más heterogéneos entre si al par que, internamente, lo más homogéneos que sea posible. Técnicamente diríamos que tratamos de construir grupos con gran varianza intergrupal y escasa varianza intragrupal. El objetivo de toda tipología es muy claro: diferenciar, dentro de un único universo, grupos diversos a tenor de una serie de características sobre las que se desea investigar. De ahí que sobre un mismo universo quepan tantas tipologías cuantas quiera el investigador (y se lo permitan los datos recolectados). Es pues preciso tener muy en cuenta que la tipología que se presenta a continuación no es la única tipología posible de familias españolas, ni siquiera con los datos que disponemos y es evidente que puedan redactarse otras distintas a la que aquí se presenta. Todo depende de la información con la que se trabaje.

Es en la constitución de la tipología donde la investigación determina sus prioridades, más que en el perfil resultante de los diferentes tipos o «clusters» que es, obviamente, una operación posterior a la previa elaboración de la tipología. Así vamos a proceder en esta presentación. En un primer momento indicaremos cómo y porqué se ha construido la tipología aquí presentada para, en un segundo momento, presentar, de forma más pormenorizada las características de cada grupo resultante y el perfil sociológico de sus miembros.

\subsection{La Construcción de la tipología}

Para la elaboración de la tipología hemos trabajado con cuatro bloques de preguntas del cuestionario administrado a los padres y madres de nuestro estudio. Es pues una tipología construida sobre las respuestas de los padres aunque, después, en el análisis también hemos tenido en cuenta las respuestas de sus hijos. Hemos buscado la imbricación interna en la familia, todas las cuestiones que se refieren al funcionamiento familiar, a las relaciones que mantienen los padres con sus hijos y la valoración que les merecen esas relaciones, las causas o motivaciones por las que pueda haber conflictos o motivos de discrepancia entre padres e hijos y por último, la importancia que conceden a una serie de valores finalistas en su vida. En total 59 informaciones diferentes, de las que la gran mayoría, 50 exactamente, se refieren a aspectos concretas de la vida 


\section{Tipología y socialización de las familias españolas}

familiar, de la relaciones de los padres con sus hijos, siendo las 9 restantes las referidas al universo nómico de los padres bajo la hipótesis subyacente que los valores tienen que ver con los comportamientos y las actitudes consiguientes.

A estas 59 informaciones diferentes, y al objeto de buscar algunas líneas de fuerza mayores, 'las hemos sometido a un factorial conjunto de componentes principales (tras haber realizado previamente sendos factoriales particularizados por bloques diferenciados para comprobar su pertinencia, factoriales que no presentamos para simplificar el texto) que ha dado como resultado haber logrado «reducir» toda la información contenida en los 59 ítems en 15 grandes factores como 15 grandes tendencias que ilustran, explicando el 56,9\% de la varianza, la dispersión de comportamientos y actitudes de los padres y madres de la sociedad española de hoy. Es lo que presentamos en el Cuadro $n^{\circ} 1$. Hemos respetado al máximo la literalidad de los ítems propuestos en el cuestionario para una recta comprensión de los factores resultantes.

CuAdro n..$^{\circ}$. Resultados del Factorial Conjunto sobre cuestiones referidas al funcionamiento familiar, relaciones de los padres/madres con su hijo/a, las causas de los conflictos familiares y los valores finalistas. (Las respuestas son las proporcionadas por los padres/madres). Explica el $56,9 \%$ de la varianza

\begin{tabular}{|c|c|c|}
\hline $\begin{array}{l}\text { Factor 1. } \\
\text { Excelente } \\
\text { comunicación } \\
\text { padres/hijos }\end{array}$ & $\begin{array}{c}\text { Factor } 2 .^{\circ} \\
\text { Conflicto por } \\
\text { drogas, } \\
\text { alcohol, } \\
\text { sexo }\end{array}$ & $\begin{array}{c}\text { Factor } 3^{\circ} \\
\text { Conflicto } \\
\text { horas } \\
\text { nocturnas, } \\
\text { levantarse }\end{array}$ \\
\hline
\end{tabular}

40. Me resulta fácil hablar de los problemas con mi hijo/a ...........

39. Mi hijo/a puede saber cómo me siento sin preguntármelo ............. 62

41. Si tuviera problemas, se los podría contar a mi hijo/a ............ $\quad .59$

49. Me resulta fácil hablar de los problemas con mi hijo/a. ..........

47. Mi hijo/a intenta comprender mi punto de vista . . . . . . . . . .

36. Mi hijo/a siempre sabe escuchar . . . . $\quad .52$

46. Cuando hago preguntas, mi hijo/a me responde sinceramente ......... $\quad .49$

50. Me resulta fácil hablar de los problemas con mi hijo/a . . . . . . . . 
42. Le muestro abiertamente afecto, cariño, a mi hijo/a . . . . . . . . . .

77. Discuten mucho por consumo drogas .

76. Discuten mucho por consumo alcohol .

79. Discuten mucho por relaciones sexuales

78. Discuten mucho por sus amistades ...

80. Discuten mucho por relación con hermanos u otros miembros familia ..

71. Discuten mucho hora levantarse cama

72. Discuten mucho por el dinero .......

69. Discuten mucho hora nocturna llegada a casa . . . . . . . . . . . . . .

73. Discuten mucho por colaboración en el trabajo doméstico .............

70. Discuten mucho por los estudios .....
.40

Factor $4 .^{\circ} \quad$ Factor $5^{\circ} \quad{\text { Factor } 6 .^{\circ}}^{\circ}$ Unidos, hacen Muy malas Relaciones cosas juntos relaciones precavidas padres/hijos padres/ hijos

21. Los miembros de la familia nos sentimos más unidos entre nosotros que en relación a otras personas ajenas a la familia . . . . . . . . . . .

20. Nos gusta hacer cosas en las que participemos sólo los miembros de la familia ..................

23. A los miembros de la familia nos gusta pasar el tiempo libre juntos ........

24. Los miembros de la familia nos sentimos muy unidos . . . . . . . . .

26. Cuando nos reunimos para alguna actividad todos estamos presentes ...

16. Los miembros de la familia nos pedimos ayuda unos a otros .......

45. Cuando hablo con mi hijo/a le digo cosas que no se deberían decir (cosas que duelen, ofenden) ........

38. Mi hijo/a me dice cosas que sería mejor que no se dijeran (cosas que duelen, ofenden) ............

2. Mi hijo/a me insulta cuando está enfadado conmigo .............

43. Cuando tenemos problemas, a menudo dejo de hablar a mi hijo/a . . . . . . . .

51. Mi hijo/a me agobia .......... 


\section{Tipología y socialización de las familias españolas}

48. Hay ciertos temas que evito hablarlos con mi hijo/a ..............

44. Tengo cuidado con lo que le cuento a mi hijo/a ................

. No creo que pueda decirle a mi hijo/a cómo me siento acerca de algunas

cosas ..................

A veces no me atrevo a pedirle a mi hijo/a lo que quiero ...........

\begin{tabular}{|c|c|c|}
\hline $\begin{array}{l}\text { Factor } 7 .^{\circ} \\
\text { Relaciones } \\
\text { abiertas, } \\
\text { anómicas }\end{array}$ & $\begin{array}{c}\text { Factor 8. } \\
\text { Valoran } \\
\text { moralidad, } \\
\text { dinero y } \\
\text { capacitación }\end{array}$ & $\begin{array}{c}\text { Factor } 90^{\circ} \\
\text { Familia } \\
\text { flexible }\end{array}$ \\
\hline
\end{tabular}

31. Resulta difícil identificar quién o quiénes son los que mandan en nuestra familia

27. En nuestra familia no hay reglas o normas fijas ...............

25. Las opiniones de los hijos acaban imponiéndose en la familia ........

91. Es importante llevar una vida moral

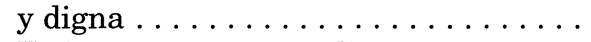

90. Es importante ganar dinero .......

89. Es importante obtener un buen nivel de capacitación cultural y profesional ...

83. Es importante tener unas buenas relaciones familiares . . . . . . . . .

22. En nuestra familia vamos adaptando la manera de hacer las cosas según las circunstancias ............

32. Los miembros de la familia pensamos que la unión familiar es muy importante

\section{.67}

.60

34. Puedo hablar de mis creencias

(ideas, opiniones) con mi hijo/a sin sentirme cohibido o avergonzado .....

\begin{tabular}{|c|c|}
\hline $\begin{array}{c}\text { Factor } 10 .^{\circ} \\
\text { Presentismo. } \\
\text { Esteta, T.L. } \\
\text { y ocio }\end{array}$ & $\begin{array}{l}\text { Factor 11. } \\
\text { La opinión } \\
\text { de los hijos } \\
\text { considerada }\end{array}$ \\
\hline
\end{tabular}

85. Es importante vivir al día sin pensar en mañana ................

86. Es importante invertir tiempo y dinero en estar guapo/a 
84. Es importante disponer de mucho tiempo libre y de ocio . . . . . . . . . .

18. Aceptan los amigos que tienen los hijos

19. Se tiene en cuenta la opinión de los hijos en las normas que les afectan ...

35. A veces me cuesta trabajo creer todo lo que mi hijo/a me dice ..........

17. A la hora de solucionar los problemas se siguen las sugerencias de los hijos

29. Nos turnamos las responsabilidades de la casa . . . . . . . . . . . . . .

28. Se nos ocurren fácilmente cosas que podemos hacer en familia .........

30. Los miembros de la familia nos consultamos las decisiones
.54

.68

.55

$-.41$

.38

.70

.56

.34

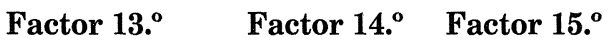

Altruismo Discuten por Tareas

Religión y domésticas

Política definidas

88. Es importante preocuparse por lo que ocurre en otros lugares del mundo ...

87. Es importante hacer cosas para mejorar mi barrio o mi comunidad .........

75. Discuten mucho por la religión .....

74. Discuten mucha por la política .....

33. Resulta fácil decir quien realiza cada tarea doméstica ............

.85

.82

.73

.60

Resumamos brevemente los contenidos de cada factor.

Factor $1 .^{\circ}$ : Factor que describe con 9 ítems las respuestas de los padres que manifiestan tener unas excelentes comunicaciones con sus hijos: pueden hablar entre sí sin problemas, muestran abiertamente sus afectos etc.

Factor 2. ${ }^{\circ}$ : Agrupa las respuestas de los padres que manifiestan discutir con sus hijos por razón de comportamientos relacionados con los consumos de drogas y de alcohol, por temas de orden sexual, por sus amigos. También discusiones entre hermanos

Factor 3.: : En este factor se agrupan las respuestas paternas que destacan por discutir respecto de la hora a la que se levantan los hijos, la colaboración en las tareas domésticas, por el dinero que gastan, por sus estudios... 


\section{Tipología y socialización de las familias españolas}

Factor $4^{\circ}{ }^{\circ}$ : Familias que no solamente están unidas sino que además valoran por encima de las demás hacer las cosas ellos solos, la familia exclusivamente.

Factor 5. ${ }^{\circ}$ : Muy malas relaciones de los padres con sus hijos: se dicen cosas que confiesan no debieran decirse, llegan al insulto...su hijo o su hija les agobia

Factor 6.: No se llevan mal con sus hijos. Tampoco son excelentes sus relaciones. Andan con cuidado a la hora de hablarse. Son relaciones precavidas las que dominan en estas respuestas

Factor 7.: : En este factor habría relaciones que hemos calificado de abiertas e incluso anómicas, en el sentido de que no se sabe bien quien manda en esa familia, donde apenas hay reglas fijas en la que, a la postre, parece que las opiniones de los hijos acaban imponiéndose.

Factor $8 .^{\circ}$ : Los padres de este factor valoran, sobre los demás, la moralidad, la capacitación cultural y profesional y también ganar dinero. Es importante anotarlo por lo que supone de introducir en el mismo esquema, moralidad, capacitación y éxito económico.

Factor 9. : : Apuestan por una reglas flexibles en la convivencia familiar, cuya unión sin embargo consideran importante hasta el punto que también destacan en la capacidad para hablar de sus creencias (ideas $u$ opiniones) con su hijo de forma desinhibida. Este factor será muy dirimente en la configuración posterior del cluster

Factor 10.: : Estos padres valoran más que los demás vivir al día, invertir tiempo y dinero en estar guapos y tener mucho tiempo libre. Posicionándose en contra de las respuestas dadas en el factor anterior, conformará el tipo más numeroso de nuestra tipología.

Factor 11.': Las opiniones de los hijos son muy consideradas por estos padres.

Factor $12 .^{\circ}$ : Familia que valora la rotación de responsabilidades, hacer cosas juntos en la familia (no son los únicos en destacar este punto) $\mathrm{y}$, aunque en menor medida consultarse las decisiones entre los miembros de la familia.

Factor 13..: Los que en más alto grado valoran lo que sucede en otras partes del mundo... y en su propio barrio o comunidad. De ahí el epíteto de altruismo

Factor $14 .^{\circ}:$ Los pocos que discuten con sus hijos por religión y política. Servirá para completar la configuración, pero en negativo (discuten aún menos que los demás) en el tipo más conflictivo de la tipología.

Factor 15. ${ }^{\circ}$ : Desdibujado y débil último factor conformado por un solo ítem que viene a decir que ya se sabe quien hace qué en la familia, fac- 
tor que no interviene en la configuración de la Topología. Ejemplo claro de que lo estadísticamente relevante puede no serlo sociológicamente.

Quince factores, quince líneas de fuerzas, quince aspectos de la vida familiar, de las preferencias, acentuaciones, modalidades de las relaciones entre los padres y los hijos que ya nos resumen bastante las 59 informaciones básicas con las que hemos partido. Sirva ya para eliminar todo intento de generalización abusiva del tipo «la familia española es... Hay muchos matices, muchas pluralidades para simplificaciones abusivas. Así y todo hay que hacer aún otro esfuerzo para concentrar la información y buscar los engarces entre los quince factores. Es exactamente lo que hace la tipologización de resultados en base a factoriales previos. Enlaza las respuestas, ya previamente agrupadas en los quince factores, en razón de las similitudes y de las diferencias de unos y otros factores, creando constructos estadísticos homogéneos de los que el investigador debe retener el que presente una mayor pertinencia analítica interna. Así llegamos, en este caso, a propuestas de clasificación entre tres y seis grupos. Tras detenido análisis retuvimos la solución en cuatro tipos que es lo que se propone en las páginas que siguen. Repitámoslo: no hay una sola tipología posible de familias. Esta es una de tantas posibles que se sostiene en tanto permite ver mas claro, con todo el rigor científico de las ciencias sociales, y con pertinencia sociológica, pensamos que evidente, en el mosaico de los múltiples modelos de familias españolas en los inicios de este siglo XXI.

CUADRo N. ${ }^{\circ}$ 2. Una Tipología de familias españolas en razón de las relaciones internas entre padres e hijos y de los valores finalistas de los padres

\begin{tabular}{|c|l|c|}
\hline $\mathbf{N}^{\mathbf{o}}$ & \multicolumn{1}{|c|}{ Denominación } & Porcentaje \\
\hline $1^{\mathbf{o}}$ & Familia familista, endogámica & $23,7 \%$ \\
\hline $2^{\mathbf{o}}$ & Familia conflictiva & $15,0 \%$ \\
\hline $3^{\circ}$ & Familia nominal & $42,9 \%$ \\
\hline $4^{\circ}$ & Familia adaptativa & $18,4 \%$ \\
\hline & Total padres $\mathrm{N}=1000$ & $100,0 \%$ \\
\hline
\end{tabular}

\subsection{Descripción de la Tipología propuesta}

A continuación vamos a presentar el detalle de cada uno de los modelos familiares propuestos. En cada caso distinguiremos la construcción del cluster, los elementos que lo componen y el perfil de sus miembros. 
Tipología y socialización de las familias españolas

\section{Familia familista, endogámica $(23,7 \%$ de las familias españolas)}

Para muchas personas, digamos que tradicionales en el sentido de que miran con agrado lo que siempre han conocido y valorado como bueno, este modelo de familia sería «el» modelo de familia. Se trata de una familia donde las responsabilidades de unos y otros están claras y son asumidas sin dificultad, por previamente sabidas y reconocidas, familia en la que las relaciones de padres e hijos son buenas (las mejores de entre los cuatro grupos que conforman nuestra tipología), que valora fuertemente hacer cosas juntos y que tiene relativa capacidad para adaptarse a las nuevas circunstancias que puedan surgir en la vida familiar. Los padres valoran fuertemente tres valores finalistas: moralidad, buena formación y dinero; características definitorias de un modelo de familia "políticamente correcto". Las opiniones de los hijos son tenidas en cuenta a la hora de tomar decisiones (aunque los componentes del grupo $4^{\circ}$ todavía destacan más en este punto).

Otros dos aspectos acaban de definir bien a este modelo y que, a la postre, han servido para etiquetar el grupo: no buscan necesariamente las relaciones externas (aún sin rehuirlas) pues parece que están más a gusto entre ellos solos que con otras gentes (es lo que hemos definido con el término de familista) y, en segundo lugar, se posicionan negativamente, respecto de la media poblacional, cuando se trata de preocuparse por lo que pasa en el mundo o en el propio barrio o comunidad (de ahí la calificación de endogámica). Parecería que están a tan a gusto entre ellos, y lo están, que se bastarían, y «lo de fuera» sería visto, si no como una molestia, sí como una intromisión innecesaria. Forzando un tanto diríamos que estamos ante una familia excelentemente avenida, preocupada por el éxito y la felicidad de sus miembros, en la que la opinión de todos es tenida en cuenta, muy probablemente tolerante con el diferente, con el de fuera...a condición de que se quede fuera 0 , al menos, de que no entre demasiado en casa. Familia muy centrada en sí misma, prácticamente autosuficiente, con distanciada preocupación por lo que sucede fuera de sus muros, capaz de procurar, y conseguir un clima cálido y agradable que sus hijos vendrán a corroborar. Obviamente, en este clima, la socialización familiar es muy importante y es uno de los dos modelos de familia (el otro será el $4^{\circ}$ de nuestro estudio) en el que la familia es el elemento central de la socialización.

Estamos ante padres con identidades fuertes (mayor presencia de católicos practicantes, pero también hay agnósticos y no creyentes por 
encima de la media), con opciones probablemente ya asentadas. Los hijos son los que menos drogas consumen de entre todos los tipos de la muestra, lo que no quiere decir, en absoluto, que no las consuman.

Este tipo de familia no parece estar condicionado por factores sociodemográficos: puede darse en cualquier grupo social, cultural o económico, y en diferente hábitat y contextos. Para no pocos, sería el modelo de familia «de siempre», ideal y relativamente añorado.

\section{Familia conflictiva (15,0\% de las familias españolas)}

De los cuatro grupos, éste es el más compacto, el más homogéneo, en las características que hemos seleccionado para realizar la tipología. Es la familia en la que sus miembros peor se llevan entre sí, donde más conflictos se dan, por causa del consumo de drogas, por las cuestiones de orden sexual de los hijos, por las amistades de éstos e, incluso, por las relaciones entre los hermanos. Las relaciones de los padres con sus hijos son, con diferencia, las peores de los cuatro grupos, y la comunicación es muy escasa o mala (cuando no muy mala). ${ }^{4}$

Para entender lo que sucede en el seno de estas familias, conviene detenerse en la ecuación nómica de los padres. Estos padres no valoran «vivir al día, la estética física, ni el tiempo de ocio», valores todos ellos en los que destacan la mayoría de los adolescentes españoles de hoy. Luego gran distancia nómica con sus hijos. Además estos padres se singularizan por no tener en cuenta las opiniones de los hijos, o por tenerla en cuenta en notoria menor medida que los demás. Así mismo determinados posicionamientos de los padres denotan ausencia de flexibilidad en las relaciones que mantienen con sus hijos, siendo, con diferencia, los que menos discuten con ellos por temas políticos y religiosas, cuestión esta que, ciertamente, puede tener muchas lecturas: desinterés (como sucede en los grupos $1 .^{\circ}$ y $3 .^{\circ}$, aunque por razones distintas en ambos), o dificultad particular para entablar discusiones sobre estos puntos en un clima de diálogo difícil (hipótesis que nos parece más plausible en este caso). En definitiva nos inclinamos a pensar que estamos ante situaciones que tienen su raíz, en no pocos casos, en los propios padres, pues presentan un universo de valores muy distante al mayoritario en los hijos, amén de una rigidez en sus propias concepciones de la familia, con una delimitación de estatus y roles paterno y filiares relativamente envarados. Las malas comunicaciones, los conflictos, pueden estar inmediatamente ocasionados por el comportamiento de los propios hijos (en este grupo en- 
contramos los máximos consumidores de drogas), pero en su raíz, en su secuencia temporal, nos inclinamos a pensar que cabe inscribirlos en la ecuación nómica de los padres.

El perfil sociodemográfico de éstos nos habla de padres con un estatus socioprofesional y un nivel de salarios conforme a la media poblacional, pero con un nivel de estudios algo inferior al de esa media. Cuando se trata de pedir ayuda para resolver los conflictos en la familia estos padres destacan, al alza, por pedir mayor actuación policial y, a la baja, por la demanda de recursos educativos. Son padres nominalmente religiosos, algo menos formalmente definidos en sus valencias políticas (inclinados a la derecha), y con unos hijos que, éstos ya en mayor proporción, son claramente no religiosos y no tienen reparo en decirse de derechas, incluso en mayor proporción que sus propios padres y más allá del posicionamiento que éstos les atribuyen.

\section{Familia nominal $(42,9 \%$ de las familias)}

Es el modelo mayoritario en nuestra sociedad. Se trata de una familia en la que las relaciones de padres e hijos pueden ser calificadas, con absoluta propiedad, como de coexistencia pacífica más que de convivencia participativa; los miembros de estas familias se comunican poco $\mathrm{y}$, menos aún, participan en afanes, preocupaciones y objetivos comunes. Los padres están, en gran medida, cohibidos, desimplicados, sin que aborden con una mínima profundidad lo que requieren sus hijos; son padres, que buscan vivir al aire del tiempo, valorando el día a día, el tiempo libre y de ocio, el estar guapos... Una familia «light», cuya unión se considera menos importante que para el conjunto poblacional, en la que las opiniones de los hijos no son, de verdad y en profundidad, muy consideradas por sus padres; una familia que destaca de las demás por ser la que, en menor grado, refiere que haya conflictos en su seno por causa de las drogas, de los consumos de alcohol, de las relaciones de los hijos con sus amigos, de las relaciones sexuales, etc., básicamente porque ha decidido no enfrentarse, no enterarse de los conflictos, no porque no haya «motivos» para ello.

No es entre ellos donde encontramos los mayores consumos de drogas, aunque sí de alcohol, pero no siempre hay relación directa entre los niveles de consumo y los conflictos y disputas familiares asociados a ellos. Hay que introducir otros elementos más: la importancia y gravedad que los padres asocian a esos consumos y, anteriormente, el nivel de segui- 
miento que realizan de los hábitos de sus hijos adolescentes. Nuestra hipótesis, en este caso (que es el mayoritario, no lo olvidemos), es que estamos ante un prototipo de coexistencia pacífica en muchas familias españolas: «las cosas son como son, los hábitos juveniles son los que son y más vale que nuestros hijos no resulten 'bichos raros'; con tal de que no se sobrepasen demasiado, es normal que se diviertan al modo como se divierten hoy los adolescentes»; algunas charlas precautorias de cuando en vez, y que la fortuna reparta suerte o, al menos, evada la peor suerte. «Cuando se vayan introduciendo en la veintena, las cosas se irán aquilatando por sí mismas», se concluye y se mira a otro lado. Obviamente no se discute con los hijos: dos no discuten si uno no quiere.

$\mathrm{Al}$ preguntar a los padres de este grupo por las cosas que les ayudarían a resolver la educación de sus hijos, exigen un mayor compromiso del otro miembro de la pareja, lo que nos indica una falla en la responsabilización conjunta de la educación de los hijos. Tanto los padres como los hijos sitúan, en comparación con los otros tipos, a los amigos como el espacio privilegiado donde se dicen las cosas más importantes para orientarse en la vida, otorgando menor grado de importancia (de forma particularmente llamativa) a los libros, a la escuela y a la iglesia. La socialización, de la que los padres parecen haber dimitido, se presenta informal, por ósmosis, y primando la horizontalidad del grupo de pares: no es de extrañar que estemos ante el modelo de familia en el que la socialización estructurada sea la más escasa de los cuatro modelos que presentamos. Los padres se posicionan como católicos no practicantes, ligeramente escorados a la derecha, fiel imagen de las tendencias mayoritarias de la sociedad de la España de tránsito de siglo a la que, por razones estadísticas (son el 43\%, no se olvide) y, también sociológicas, reflejan y representan.

\section{Familia adaptativa $(18,4 \%$ de las familias $)$}

He aquí el modelo de familias nacientes: es el más moderno, el que mejor refleja las tensiones de las nuevas familias. Frente a los perfiles relativamente estereotipados de los modelos anteriores, que los hacen fácilmente perceptibles e identificables, este cuarto modelo exige un esfuerzo de abstracción, imaginación y prospección. Probablemente, lo señalamos de entrada, bajo su denominación se esconden variantes que no podemos tener en cuenta dada la escasez de la submuestra, 144 padres, que aunque extrapolables a 184 , no permiten desgajamientos con 
Tipología y socialización de las familias españolas

cierta seguridad estadística. Gran parte de los nuevos e incipientes modelos familiares de los que hablan los sociólogos de la familia cabrían en este «macromodelo». ¿Como definirlo?. Por la búsqueda de acomodo, de adaptación a las nuevas condiciones, a los nuevos papeles del hombre y de la mujer de hoy en el microcosmos familiar, al creciente protagonismo de los hijos que vienen pidiendo autonomía nómica (quieren crear "su» universo de valores), y que también pretenden libertad en el uso y disfrute del tiempo libre al par que acompañamiento (discreto pero efectivo) de los padres en su inexorable autonomización. Unos hijos que están dispuestos a llevar esa autonomía a la práctica en el modo de vivir con sus pares, en los estudios, en el trabajo (los que se deciden a trabajar y pueden hacerlo) pero, siempre, entendiendo que su hogar familiar de origen, el de sus padres, seguirá siendo el suyo hasta bien entrada la veintena (si no es la treintena ya cumplida), cuando se decidirán, no antes, a crear su propio espacio. Los padres que intentan gestionar estos hijos y la interrelación que se establece entre todos, padres e hijos, conforman este cuarto modelo de familia.

Se trata de una familia con buena comunicación entre padres e hijos, con capacidad de transmitir opiniones y creencias, abierta al exterior aún valorando la dimensión familiar donde las opiniones de los hijos son particularmente tenidas en cuenta. Pero, aún siendo cierto todo lo anterior, es una familia no exenta de conflictos, de desavenencias, a veces graves, fruto básicamente de situaciones nuevas en los papeles de sus integrantes, mujer y hombre, madre y padre, padres e hijos. A diferencia de lo que sucede con el grupo primero, en el que los roles y estatus están claros, en este modelo las responsabilidades de cada uno están en revisión continua y el trabajo o las acciones familiares, en tanto que familiares, no resultan evidentes y son objeto de tanteos y de incertidumbres. De ahí la presencia de conflictos derivados de un ajuste de roles en las nuevas estructuras familiares y de relación, de la necesidad de ir creando una nueva cultura, de la búsqueda conjunta de un acomodo ante las nuevas formas de trabajo y ocio de las generaciones emergentes, ante las exigencias de autonomía de los adolescentes (que unos padres, con más formación que la media y con unas ideas, llamémoslas así, progresistas, no pueden no escuchar aunque no siempre estén dispuestos a aquiescer). Estos padres piden más y mejores recursos para el ocio y el tiempo libre, así como para el sistema educativo; también piden ayudas fiscales y créditos más asequibles para las familias; a la vez son los que, en menor grado, solicitan que la policía aumente sus controles. Estos padres también son los que, más frecuentemente, sitúan a los centros educativos como los lugares 
donde se dicen las cosas más importantes para orientarse en la vida, y los que, en más alto grado, intentan inculcar en sus hijos la solidaridad, la tolerancia y el respeto a los demás, así como la honradez y la lealtad (con resultados no siempre satisfactorios, todo hay que decirlo). Otro rasgo clave es que es una familia que, aún valorando fuertemente la vida intrafamiliar, está muy abierta al mundo exterior; sus miembros no son familistas y endogámicos como los del grupo primero. Entre esos miembros hay agnósticos, no creyentes y ateos por encima de la media, especialmente en los hijos. Éstos últimos también consumen más drogas que la media, aunque bastante menos que los del tipo de la familia conflictiva.

Esta familia (mosaico de familias, más exactamente) que hemos denominado adaptativa, emergente parece ser la familia de la «negociación", de la búsqueda, del acomodo, no llegando siempre y, menos aún a corto plazo, a los resultados deseados. Pero, las que atraviesen con éxito la prueba de la adaptación a la modernidad, permitirán a las nuevas generaciones insertarse con mayores garantías en la sociedad del futuro. Ausencia de conflicto en la adolescencia, en el seno de las familias, no es garantía de solidez en las estructuras nómicas adquiridas y conformadas con las que andar por la vida, ya adultos, con criterios autónomos.

\section{Concluyendo}

El grupo primero, la familia añorada y, justamente por más de una razón, tiene el handicap de un enrocamiento excesivo en si misma, con una mirada básicamente precautoria hacia el exterior, exterior con el que algún día los hijos tendrán que enfrentarse, ya fuera del nicho familiar. Esta familia tiene capacidad para transmitir los valores de los padres. La duda, nuestra duda, está en si la transmisión de valores, realizada, en este caso, por reproducción de lo inculcado por sus padres se ha hecho propia, esto es, si ha pasado por cedazo de la duda y la confrontación personal al modo como se realiza la socialización en la mayoría de la juventud actual, sobretodo cuando tal socialización tiene alguna espesura.

Espesura, consistencia, una mínima estructura es, precisamente, lo que no tiene capacidad de trasladar el tercer colectivo, el mayoritario, el que hemos denominado familia nominal. Es en este modelo en el que se piensa, y con toda razón, cuando se habla de la incapacidad de la actual familia para transmitir valores. Así y todo hay que añadir que aunque conforma casi la mitad de las familias, tampoco cabe generalizar al conjunto de familias españolas. 


\section{Tipología y socialización de las familias españolas}

El grupo segundo puede ser considerado como el reverso del primero. Forzando un tanto la comparación diríamos que si en este los hijos corren el riesgo de adoptar, acríticamente los valores que les inculcan sus padres, los hijos del segundo grupo, al que hemos denominado conflictivo, recuérdese, corren el riesgo, a su vez; de adoptar no solo valores sino comportamientos, en oposición a los valores dominantes de sus padres. De nuevo quedará en duda lo que advengan en el futuro pero, ya en el momento presente, además de ser los más conflictivos en casa, presentan los mayores consumos de drogas que no de alcohol (donde se singularizan los hijos de la familia nominal), significando en ello, en este punto de los consumos de alcohol y drogas, la mayor distancia social sobre el modelo dominante en los componentes del grupo segundo y la menor en los del tercero.

En fin, las familias adaptativas, corren el riesgo de rupturas por desentendimientos entre padres e hijos, cuando no en la propia pareja (arrojan la mayor presencia de parejas separadas y están en la capa social en la que estas situaciones se dan con más frecuencia). De ahí, entre otras causas, la presencia de conflictos en su seno, pero la preocupación por los hijos, los intentos de diálogo, la preocupación y, relativa, implicación por lo que sucede más allá de los muros familiares, hacen pensar que estamos, además de ante los modelos de las nuevas familias, aquellas en las que, junto con las familias del primer grupo, haya transmisión estructurada de valores y, cuando las cosas vayan bien, mayor probabilidad de que los hijos se adapten, autónomamente, a la nueva sociedad.

\section{Bibliografía}

AlBerdi I. (1999) «La nueva familia española» Madrid. Ed. Taurus.

Barea J., Cabrillo F., Del Campo S., Cortina A. Durán i lleida J.A., Gámir L., García EchevarRía S., Iglesias de Ussel J., Iranzo J.E., Lipovetsky G., Montoro R., Pérez L., SÁez F., Termes R. y VAlle V. (2000) «Dimensiones económicas y sociales de la familia» Madrid. Fundación Argentaria. Visor.

CAmpiche J. Roland (dir) «Cultures jeunes et religions en Europe». Ed du Cerf, París 1.997, 386 páginas.

DEL CAMPo SAlustiano. «La «nueva» familia española «(Eudema, Madrid 1981 y 1995)

CEPS. (1999) «Estudio sobre factores de riesgo y protección de carácter familiar relacionados con el uso y abuso de drogas en adolescentes del municipio de Madrid». Madrid. Plan Municipal contra las Drogas del Ayuntamiento de Madrid.

Cruz Cantero P., SANTIAgo Gordillo P. (1999) «Juventud y entorno familiar» Madrid. Injuve.

Elzo J. (dir.), Orizo Andrés F., González-Anleo J., González Blasco P., Laespada M-T., Salazar L. «Jóvenes Españoles 99». Fundación Santa María. Ed. S.M. Madrid 1999. 
ELZO JAVIER «El silencio de los adolescentes». Ediciones Temas de Hoy.Madrid 2.000, 230 páginas

Elzo J. y ORIzo Andrés F. (directores), Ayerbe M., Corral J., Díez Nicolás J., GonzálezAnleo J., González Blasco P., Setién M.L., Sierra L., Silvestre M., Valdivia C. «España 2000, entre el localismo y la globalidad. La Encuesta Europea de Valores en su tercera aplicación, 1981-1999». Universidad de Deusto. Ediciones S.M. Madrid 2000.

ELzo JAVIER «La familia española de hoy como agente de socialización». En «Veintiuno. Revista de Pensamiento y Cultura», n 50, Verano de 2001. páginas 73-82. Edita Fundación Canovas del Castillo. Madrid 2001.

ELzo JAVIER en Aspectos de la cultura juvenil. (páginas 95-118) en «Sociedad y drogas, una perspectiva de 15 añ்s». Edita $\mathrm{FAD}$, Madrid 2002. 257 páginas.

Elzo JAVIER (dir). «Drogas y Escuela VI». Ed. Escuela Universitaria de Trabajo Social. San Sebastián 2003.

ELZO JAVIER. «Familia y religión: ¿libertad religiosa o confrontación». (páginas 401-431) en Dionisio Borobio (Coordinador), «Familia e interculturalidad». Publicaciones de la Universidad Pontificia de Salamanca. 474 páginas. Salamanca 2003.

EUROSTAT, Anuario 97: Visión estadística sobre Europa 1986-1996, Oficina de Publicaciones Oficiales de las Comunidades Europeas, Luxemburgo, 1997.

EUROSTAT, Social Portrait of Europe, Office for Official Publications of the European Communities, Luxemburgo, 1998.

FAD (2000) «Prevención del consumo de drogas en el ámbito familiar. Manual de prevención». Madrid. Área de Servicios Sociales del Ayuntamiento de Madrid.

FlaQUeR Ll. (1998) «El destino de la familia». Madrid. Ed. Ariel.

GarRido Medina, Luis y Gil Calvo, EnRIQUe (eds.), Estrategias familiares, Alianza, Madrid, 1993.

GonzÁlez Blasco Pedro, (dir), Francisco Andrés Orizo, Francisco Javier Elzo Imaz, José Juan Toharia Cortés, «Jóvenes Españoles 89» Edit. Fundación Santa María. Ediciones S.M. Madrid 1.989. 380 páginas.

IgLeSIAS DE Ussel, J. «La familia y el cambio político en España», Tecnos, Madrid, 1998.

Iglesias de Ussel J., Flaquer I., Meil G., Alemán C., Trinidad A. (1994) «Familia en V Informe sociológico sobre la situación social en España. Sociedad para todos en el año 2000». Vol. 1. 1994. Ed. Fundación FOESSA págs. 415-554.

INSTITUTO DEUSTO DE DROGODEPENDENCIAS (2000) «Las familias y sus adolescentes ante las drogas». Bilbao. Universidad de Deusto. Bilbao, 2001.

Martín Serrano, M. y Velarde Hermida, O. «Informe Juventud España 2000». Injuve. Ministerio de Trabajo y Asuntos Sociales. Madrid 2001

Martín Serrano, M. (2001) :Informe Juventud en España. Madrid, INJUVE.

Eusebio Megías (dir), Domingo Comas, Javier Elzo, Ignacio Megías, José Navarro, Elena Rodríguez, Oriol Romaní. «Valores sociales y drogas».Edita FAD, Madrid 2001. 382 páginas.

MegíAs Eusebio (coordinador), Javier Elzo, Ignacio Megías, Susana Méndez, Francisco José Navarro, Elena Rodríguez «Hijos y Padres: comunicación y conflictos».. Edita FAD, Madrid 2002. 344 páginas.

PASTOR Gerardo: «La familia en España: sociología de un cambio». Ed. Sígueme. Salamanca 2002.

Pérez-Alonso Petra M ${ }^{\mathrm{a}}$ y CANOVAS PAZ, (2002):, Valores y pautas de interacción familiar en la adolescencia (13-18 años), Fundación Santa María. Ediciones S.M. Madrid 2002. 


\section{Tipología y socialización de las familias españolas}

RODRÍGuez E., MEGÍAS I., SÁNCHEZ E. (2002) «Jóvenes y relaciones grupales». Madrid. FAD e INJUVE.

ZuCKERMAN M., EYSENCK, S.B. Y EYSENCK, H.J. (1978) «Sensation seeking in England and America: cross cultural, age and sex comparisons», Journal of Consulting and Clinical Psychology, 1.

\section{Notas}

1 En consecuencia algunos de los materiales que aquí presentamos han sido ya objeto de debate e incluso de publicación. Sin embargo, el texto que aquí ofrecemos tiene prolongaciones respecto de lo ya publicado, su articulación interna es propia y determinados aspectos son absolutamente inéditos, particularmente los de una investigación sobre escolares vitorianos, con trabajo de campo de noviembre de 2002 , de los que sacamos a la luz algunos datos que nunca han sido objeto de presentación ni de publicación. (JE).

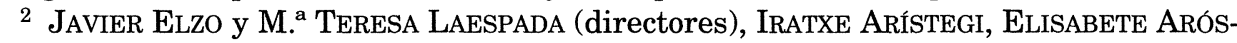
tegi, Araceli Fernández, Nieves García del Moral, Concha Maíztegi. "El consumo de drogas en escolares vitorianos». IDD. Universidad de Deusto. 2003.

3 «Hijos y Padres: comunicación y conflictos». EUSEBIO MEGÍAS (coordinador), JAVIER Elzo, Ignacio Megías, Susana Méndez, Francisco José Navarro, Elena Rodriguez. Edita FAD, Madrid 2002. 344 páginas. En el País Vasco poco antes se llevó a cabo otro estudio con características similares promovido por la Universidad de Deusto. Ver Isabel Vielva, Luis Pantoja, Juan Antonio Abeijón (eds). "Las familias y sus adolescentes ante las drogas». IDD. Universidad de Deusto, 250 Páginas, 2001.

4 Conviene recordar que una tipología no es una separación de grupos en departamentos estancos. Se trata de acentuaciones respecto de un valor medio. Decir que los componentes de un grupo, por ejemplo el conflictivo que ahora estamos presentando, se llevan mal entre sí, no significa que estén todo el día tirándose los trastos a la cabeza. Significa que, en relación a la media poblacional, son los que peor se llevan, los que más discuten, los que peor comunicación tienen. Es una apreciación de orden cualitativo (que hemos cuidado en la redacción con el uso de epítetos ajustados a cada caso) pero que para su cuantificación exige dirigirse a las tablas, tanto las de los cuadros definitorios del Cluster como las tablas pormenorizadas del Anexo al capítulo 7. (Megias E. FAD 2002, páginas $157 \mathrm{y} \mathrm{ss).}$ 